\title{
LA FUNDACIÓN DE LIMA Y LA CREACIÓN DE UNA NUEVA MITOGRAFÍA AMERICANA
}

\author{
Martina Vinatea \\ Universidad del Pacífico
}

Recibido: 19-11-2016

Aprobado: 24-02-2017

\begin{abstract}
Martina Vinatea Recoba, doctora en Filología hispánica, es profesora principal de la Universidad del Pacífico (Lima, Perú), Premio extraordinario de investigación 2013-2014, y codirectora del Centro/Proyecto de Estudios Indianos de la Universidad de Navarra y Universidad del Pacífico. Sus últimos trabajos se han centrado en la poesía femenina conventual hispánica y del Perú colonial; y en las obras de los poetas de la Academia Antártica.

vinatea_rm@up.edu.pe
\end{abstract}

\section{RESUMEN}

El propósito del presente artículo es examinar el poema "Fundación y grandezas de la muy noble y leal ciudad de los Reyes de Lima" de Rodrigo de Valdés (1687), como un discurso fundacional cuyo objetivo es crear una nueva mitografía que reinterprete la herencia latina desde una perspectiva americana. El Poema tiene como objetivo trasladar la mitología griega y latina al Nuevo Mundo recrear la mitografía - con la finalidad de fundar una nueva mitología que consolide a las nuevas tierras y que se convierta en discurso político y moral para sustentar la nueva realidad americana.

En esta obra literaria, Valdés ofrece una visión de Lima mediatizada por sus sentimientos, sus sensaciones y sobre todo su afán de elevarla como el lugar donde habitan los "beneméritos" cuyo padre es simbólicamente Pizarro presentado como el héroe de la conquista - y cuya mayor gloria es Rosa, la santa de Lima. Así, Lima encarna el tópico de la ciudad perfecta, que permite practicar la virtud y llegar al bien común; descripción necesaria para construir una idea del Nuevo Mundo como una prolongación de España: sede del mayor imperio de cristiandad.

\footnotetext{
ABSTRACT

Rodrigo de Valdes' poem "Fundación y grandezas de la muy noble y leal ciudad de los Reyes de Lima" (1687) has as objective to bring up Greek and Latin mythology to the "New World" recreating mythography - with the purpose to found a new mythology which consolidates the new conquered territories and to serve as political and moral speech to support the new American reality.

In this piece of literary work, Valdes offers a vision of Lima based upon his feelings, sensations and above all his eagerness to establish it as the place where "worthies" live, whose symbolic father is Pizarro - presented as the conquest hero - and whose major glory is Rosa, Lima's saint. Thus, Lima is meant to represent the perfect city, which allows the practice of virtue and to accomplish common welfare; description seemed as necessary to build up the idea of the New World as a continuum of Spain: the major empire of Christianity.

In this way, the aim of this article's author is to examine this poem about Lima's foundation, as a foundational speech whose objective is to create a new mythography which is able to reinterpret the Latin heritage from an American perspective.
} 
Mi propósito es examinar el Poema sobre la Fundación de Lima, de Rodrigo de Valdés (1687), como un discurso fundacional que tiene por objetivo crear una nueva mitografía que reinterprete la herencia latina desde una perspectiva americana.

De acuerdo con el maestro Ruiz de Elvira,

\begin{abstract}
Mitografía es el conjunto de las obras literarias antiguas que en griego y en latín tratan de la mitología ya sea en forma sistemática, ya en alusiones o en utilizaciones de cualquier clase o extensión. Una gran mayoría de las obras de la poesía clásica están incluidas dentro de la mitografía: cada una de ellas ofrece algunos datos que sirven para la comprensión de las demás, y a su vez cada una de ellas, para poder ser comprendida, necesita igualmente de los datos ofrecidos por algunas otras (Ruiz de Elvira, 1964: p.1).
\end{abstract}

El poema, cuyo título completo es Fundación y grandezas de la muy noble y leal ciudad de los Reyes de Lima, insigne corte, cabeza tres veces coronada del Perú, rico, lucido esmalte de la corona de España que ciñe al círculo eterno de dos mundos, nuestro augusto invicto monarca, tres veces grande emperador de las Indias: celebradas a coros de una y otra lengua, en cuartetas heroicas de verso hispano latino, califica, en tanto poema latino, como mitografía y en las páginas siguientes veremos cómo no solamente es una obra que trate del tema mitológico, sino que tiene como objetivo trasladar la mitología griega y latina al Nuevo Mundo con la finalidad de inventar una nueva mitología, una mitología fundacional que se convierta en discurso político y moral para sustentar la nueva realidad americana y equiparar a los nacidos en América con los peninsulares.

En el primer canto, el yo poético anuncia su propósito: cantar a Lima a quien presenta como el sol que ofrece benéficas luces para iluminar las heroicas y sublimes causas; es decir, los motivos, las razones que llevaron a fundar la capital de los nuevos reinos del Perú, que resulta un espacio privilegiado de la geografía de lo maravilloso. La conquista y fundación de Lima se traducen en glorias inmortales y en inmensas gracias, beneficios, dones. Es una metrópolis de tanta majestad que ostenta en un esclarecido lugar de su escudo las tres coronas de los reyes magos, cuyos restos descansan en Colonia. Cuando la noche usurpa la luz del día, Lima sigue coronada, pues en el firmamento se aprecian las siete estrellas que conforman la corona que Baco dio a Ariadna, que es perúvica o peruana. Lima, al igual que Ariadna con Teseo, da hebras -en realidad, abundantes minas- de oro a los cristianos españoles para salvarlos, tal cual hizo Ariadna con Teseo. 
¡Oh, no quiera Dios que sean tan ingratos los españoles con Lima como lo fue Teseo con Ariadna, dejándola acabar y consumir en lo retirado de este nuevo mundo! La metrópolis limeña usurpa sus esplendores a la constelación de Ariadna, porque brilla como ese astro. Además de las tres coronas en el escudo de Lima figura una estrella de oro. En la esfera es famosa la constelación que llamaron con nombre de Ariadna, porque Lima hace lo mismo que hizo Ariadna con Teseo, con los españoles, dándoles las hebras de oro de las ricas minas del Perú, mujeres honrosas, estado, honor y estimación (De Valdés, 1687).

Después de esta introducción, se dirige a la "musa ambidiestra" quien ayudará a cantar adecuadamente a Lima. Esa musa no es la que escribe con las dos manos, sino esa que le permite escribir en latín y en español, para que le ministre voces sonoras que resonando convenidamente se sientan neutrales; es decir, se entiendan en los dos idiomas de las Hesperias, Italia y España. Ellas se reconocerán en la alternancia de su mezcla, aparentemente discorde, pero que en realidad se corresponden como si de sonidos idénticos se tratara. Las sirenas de España y de Italia, representadas por Parténope, colaborarán para que las disonancias concuerden por combinación artificiosa y que todo se comprenda en las dos lenguas. Aunque parezcan disonantes y que no concuerden, las dos lenguas combinadas artificiosamente podrán conseguir frases tan altas que puedan describir todas las maravillas del mundo mítico que también rinden tributo y homenaje a la Roma del Nuevo Mundo, a Lima: el erudito palacio de Minerva tritonia, las benévolas influencias de la castísima Diana, las artes libres de Mercurio, la ilustre ascendencia de Febo, la dignidad divina de Jove, los triunfos bélicos de Marte, las tan blandas, como frecuentes inclinaciones de Venus, los triunfos navales de Neptuno, las justas sentencias de Astrea, los solemnes altares de Vesta, las alfombras de césped de Flora, las dulces plantas de Pomona, las paces de la diosa Concordia, los pomposos fulgores de Himeneo, las cornucopias que en señal de abundancia muestra Amaltea, los amenos campos de Vertuno, las auras vitales de Eolo que ignoran las tristes iras inhumanas de Saturno. Termina el canto invocando a la diosa Fortuna, inspiradora de nobles audacias, para que le permita prosperar en tan ardua pretensión de escribir el poema hispano-latino. 
Lima, la ciudad más importante de América del Sur desde inicios del siglo XVII (Vinatea, 2009: p.16-26), es descrita en múltiples textos ${ }^{1}$ mediante un "discurso que busca la apropiación del espacio y del tiempo para establecer una continuidad entre la tradición europea y la clásica" (Coello, 2011: p. 87-111). Es un lugar remoto que despierta la curiosidad y es capaz de acoger el prodigio: un escenario nunca visto ni oído (Arellano, 2003: p. 41-68). Pareciera ser la "ciudad de Dios" de San Agustín; en ella se encarna el tópico de la "ciudad perfecta" que permite "practicar la virtud y llegar al bien común" (Borrego, 2003: p. 69-90). Se la exalta por su esplendor y se la designa como nueva Roma, porque rápidamente se convierte en una urbe rica y compleja, un centro político y comercial de gran importancia y una monumental ciudad barroca, donde cobran especial relieve las edificaciones religiosas. Asimismo, debemos precisar que los criollos describen de este modo Lima, porque necesitaban construir una idea del Nuevo Mundo como prolongación de la España sede del poder del mayor imperio de la cristiandad. Esa construcción debía expresarse en un relato fundacional mítico que permitiera constituir al Nuevo Mundo como un paradigma dentro del sistema de representaciones establecido por el imaginario imperial y consolidar una imagen simbólica de Lima y así consolidar una "mitografía criolla" (Vélez, 2007: p.357-389).

Luego de presentar el argumento, el yo poético dedica su obra al príncipe Carlos, quien después se convertiría en Carlos II de España, el último rey de la dinastía Habsburgo.

El canto a Lima empieza propiamente en la décima parte y lo hace a partir de la descripción del Triunfo y paseo del Real estandarte o pendón de Lima cuya divisa son las letras de los nombres de Carlos $\vee$ y su madre Juana. El pendón, representación de los reyes quienes le dan su nombre, saludan a Lima del siguiente modo: "Salve dulcísima Lima, Roma salve americana" (De Valdés, 1687) y la describe como devota, festiva, religiosa, profana y católica. Su luz oriental, que evoca a la estrella de Belén, se opone a las herejías y a las astucias dignas de Herodes, que mandó matar a los inocentes. Esas luces o avisos fueron proféticas en Arabia, se hicieron presentes en Belén y ahora anuncian las glorias de Lima y son presagio de claras victorias. Además, Lima

1 S.J. Bernabé Cobo y Peralta, Historia del Nuevo Mundo (1639); Buenaventura de Salinas y Córdoba, Memorial de las historias de Nuevo Mundo: Perú (1630); Rodrigo de Valdés, Fundación y grandezas de la muy noble y muy leal ciudad de los reyes (1687); Luis Antonio de Oviedo y Herrera, Vida de Santa Rosa de Santa María, natural de Lima, y patrona del Perú (1711) 
posee la riqueza de las tres arabias, la importancia de Belén, los perfumes de Pancaya. En suma, un lugar perfecto solamente comparable con Roma. Y como si esto fuera poco, se insiste en la idea de que sería muy difícil hallar un lugar mejor para que nazca la "flor de Lima", Rosa de Santa María.

A lo anterior, se suman las hazañas de los conquistadores personificados en Pizarro: el descubrimiento del Mar del Sur y la posesión en nombre de los reyes de España de los nuevos reinos. Los conquistadores, católicos argonautas, se comparan con centauros marinos que profanan los reinos de Neptuno. Es tan grande el descubrimiento que Europa observa atónita, Asia se muestra confusa y África incrédula. Se debe recordar que el descubrimiento del Nuevo Mundo exacerba la imaginación de los europeos, la mirabilia fascina, y sienten que en América, tierra ignota, cobran vida todos los mitos: El dorado, la atlántida y donde habitan las criaturas mitológicas: dragones, sirenas...

Pizarro es presentado como héroe, centauro, viracocha ${ }^{2}$, quien al conquistar un nuevo mundo demolió las imaginarias columnas de Hércules que aseguraban que no había tierra más allá. El yo poético le pide a Clío que ayude a cantar "de Pizarro diligencias" (De Valdés, 1687); es decir, aquellos medios e industrias que empleó con el fin de conquistar el Perú y fundar Lima. En el poema, Pizarro es el gran héroe de la conquista y quien por una suerte de predestinación es quien debe fundar Lima, el edén donde nacerá la rosa más fragante y esperada. Es un generoso ramo de una incombustible zarza: alusión mitificadora a la zarza que vio Moisés arder sin consumirse, que generalmente simboliza a Cristo o a la Virgen, pero que, en el poema, pondera la 'incombustibilidad' o perennidad de las glorias de Pizarro. La zarza es imagen de la patria de los Pizarro, que sigue produciendo ramos de esa planta.

Siguen las fundaciones de las ciudades de los reinos del Perú a quien Valdés compara con la estatua de Nabucodonosor:

\footnotetext{
No es menos semejante la semejanza del Perú con la estatua de Nabucodonosor: corre el Perú de Norte a Sur como un gigante, cuerpo compuesto de varios metales: la cabeza es el Cuzco, la corona, Lima, el pecho y brazos la provincia de Charcas, el resto del cuerpo, más al mediodía Coquimbo. En los términos del Cuzco, están las minas de oro de Carabaya, de que se forma la cabeza. En las
}

\footnotetext{
${ }^{2}$ Voz quecha que significa 'Hijo de la espuma'.
} 
provincias de los Charcas, Potosí y otros minerales de plata que componen el pecho y los brazos. En Coquimbo se da el cobre de que se hace el resto del cuerpo. Por los pies de barro y hierro son significados dos pueblos, conviene a saber, indios y españoles. Duros los unos como el hierro, por su valor y braveza, como lo han mostrado muy señaladamente en las conquistas y descubrimiento de este nuevo mundo" (De Valdés, 1687).

La primera fundación en los reinos del Perú se realiza en Cajamarca, después de la muerte de Atahualpa, el último inca. En el canto trece, continúa la historia con la supuesta traición del intérprete Felipillo, quien enamorado de una de las concubinas el inca, fabrica una traición que termina con el ajusticiamiento del Inca en perjuicio de la reputación de la conquista y el inicio de la discordia entre Pizarro y Almagro que termina en guerras civiles. Asimismo, introduce el tema de los alegatos por las restituciones de los derechos en las ricas tierras de los reinos del Perú de los "beneméritos" o descendientes de los conquistadores, los criollos que creían tener más derechos que los funcionarios peninsulares que acompañaban a los virreyes. Después funda Jauja como capital. Debe repararse en el nombre de la ciudad: la legendaria tierra cuyo significado se vincula con "gran abundancia de bienes y placeres". Francisco de Xerez la describe como "muy grande y está en un hermoso valle; es tierra muy templada: pasa cerca del pueblo un río muy poderoso; es tierra abundosa" (Canavaggio, 2003: p. 91-101).

Después, los cantos referidos a la primacía de Lima en comparación con las más importantes ciudades europeas ${ }^{3}$, Lima es presentada como una tierra tan rica y tan buena que la maldad no tiene cabida. Inclusive no se ha visto jamás un energúmeno, pareciera que los espíritus malignos estuvieran impedidos de entrar a Lima. El mal es ajeno a la capital, porque es una ciudad tan bella, donde la estética de sus edificios, sus plazas, sus conventos, sus puentes son mejores y más suntuosos que los europeos. La pila de la plaza de armas, los pozos de agua, el puente que lleva a la alameda, las iglesias y los conventos, que son verdaderas ciudades dentro de la ciudad, la casa de la moneda: todo es muestra del esplendor de tan bendecida ciudad.

\footnotetext{
${ }^{3}$ Cantos 16 a 32.
} 
Se suceden las maravillas astronómicas que determinan el temple del clima:

\begin{abstract}
La mitad del año goza Lima del privilegio y favor que gozaron los hijos de Israel en el desierto, por las nubes que la defienden del sol, con que todo el día parece una muy fresca y apacible mañana. $Y$ es cosa digna de admiración cuán necesario es el rocío destas nubes, pues con tener tan a la mano el agua del río que se reparte en tantas acequias, en no lloviendo este escaso rocío, son menos fértiles las cosechas (De Valdés, 1687).
\end{abstract}

Siguen las alusiones a la fecundidad de los valles que ofrecen soñadas frutas:

\begin{abstract}
La maravilla de ejemplo de las hoyas de pisco, que sin riego, ni otro cultivo llevan la mejor y más sazonada fruta del reino; y lo que excede todo encarecimiento es que las palmas desmintiendo lo ingrato de que son notadas, dan al tercer año hermosísimos dátiles, que no solo se pueden coger a mano, sino arrastrar por el suelo. $Y$ afirman, por cierto, que si se plantan al tercer día de luna dan fruto a los tres años; si al cuarto día, al cuarto año; y si pasan del quinto, se hacen tardías. Y los dátiles que dicen ser injertos en higueras, exceden con gran ventaja a los mejores de Berbería (De Valdés, 1687)
\end{abstract}

También describe poéticamente frutas como las granadillas, plátanos, tunas, piñas, vides - que se han adaptado a tan grato clima que hasta son aromáticas-, palta, guayaba, chirimoya; es decir, Lima es un auténtico edén. Por todo ello, Lima es apetecida por piratas, pero triunfan los defensores de esta Roma del Nuevo Mundo. Además de lo mencionado, Lima es docta, tiene la Universidad de San Marcos y los famosos colegios jesuitas:

Puede la Universidad de Lima, por muchos títulos, compararse a las más ilustres de la Europa, sino en el número de los cursantes, si en la doctrina, sabiduría y letras de sus maestros, doctores y catedráticos, así teólogos como juristas, de donde han salido tan ilustres prelados y ministros regios, y da de esto muy buena prueba en las muchas honras con que exalta los ingenios de este reino diciendo se debe hacer más estimación de ellos que de todos los ricos tesoros del Perú". En la universidad y los colegios, a la par de los misterios más altos de la fe católica, se estudia la lengua de los nativos, el quechua (De Valdés, 1687). 
También destacan los conventos femeninos, por sus bellos edificios y sus altas rentas:

\begin{abstract}
Son insignes las religiones que ilustran esta venturosa ciudad, cuyos hermosos y grandes conventos, suntuosos templos, grandes rentas, continuas limosnas, observancia, santidad, ejemplo, sabiduría y número de religiosos, excede toda ponderación, que no podrá cabalmente referir la puntualidad, riqueza, majestad y decoro, con que se celebran los oficios divinos, que es el mayor crédito de España, ver en tan remotas regiones tan fervorosa la religión cristiana (De Valdés, 1687).
\end{abstract}

Los prodigios del cerro de Potosí ocupan un canto, igual que la fabricación de galeones en Guayaquil.

Todo en Lima es maravilla y esplendor, porque es el lugar donde se "libra" la mayor gloria: el patrocinio de la purísima Rosa de Santa María, hija predilecta de la capital de los reinos del Perú. Rosa podría inspirar la envidia de encumbradas ciudades como Viterbo ${ }^{4}$. La "tan benéfica rosa de salutífera fragancia" (De Valdés, 1687) recrea, deleita a los dos mundos. Sus reliquias operan inefables favores. Rosa, esposa de Cristo, lleva como arras sus tormentos y mortificaciones. Para ella, porque así lo merece construyen suntuosas basílicas que son la expresión del amor que Lima le tiene.

La visión de Lima que Valdés en el poema Fundación y grandezas de la muy noble y leal ciudad de los Reyes de Lima nos ofrece está mediatizada por sus sentimientos, sus sensaciones y sobre todo su afán de elevarla como el lugar donde habitan los "beneméritos" cuyo padre es simbólicamente Pizarro y cuya mayor gloria es Rosa, la santa de Lima, como lugar donde se recrea la mitografía, el lugar a donde se traslada la mitología griega y latina con la finalidad de fundar una nueva mitología que consolide a las nuevas tierras y que se convierta en discurso político y moral para sustentar la nueva realidad americana.

\footnotetext{
${ }^{4}$ Donde otra santa del mismo nombre dio fama a su ciudad, en el siglo XIII
} 


\section{BIBLIOGRAFÍA}

Arellano Ayuso, Ignacio (2003) "Espacios de la maravilla en los dramas de Calderón". En: Arellano Ayuso, Ignacio (ed.). Loca Ficta: los espacios de la maravilla en la Edad Media y Siglo de Oro. Madrid: Iberoamericana-Vervuert: pp. $41-68$

Borrego Gutiérrez, Esther. (2003) "Motivos y lugares maravillosos en las cuatro bodas de Felipe II". En: Arellano Ayuso, Ignacio (ed.). Loca Ficta: los espacios de la maravilla en la Edad Media y Siglo de Oro. Madrid: Iberoamericana-Vervuert: pp.69-90

Canavaggio Cervantes, Jean. (2003) "La tierra de Jauja, de conseja a paso". En: Arellano Ayuso, Ignacio (ed.). Loca Ficta: los espacios de la maravilla en la Edad Media y Siglo de Oro. Madrid: Iberoamericana-Vervuert: pp. 91-101

Coello de la Rosa, Alexandre. (2011) "Alonso de Solórzano y Velasco y el patriotismo limeño (siglo XVII). En: Illes Imperis (2GL) 1: Estudios de historia de las sociedad en el mundo colonial y post-colonial. No vol. (Núm. 14): pp. $87-111$

De Valdés, Rodrigo. (1687) "Fundación y grandezas de la muy noble y muy leal ciudad de los reyes", Madrid: Imprenta de Antonio Román

Ruiz de Elvira Prieto, Antonio (1964) "Mitografía". Anales de la Universidad de Murcia. Filosofía y Letras. Vol. 22 (Núm. 3-4): pp.1.

Vélez Marquina, Elio. (2007) "Santa Rosa y la simbología sacro imperial". En: Lexis: Vol. XXXI (Núm. 1-2): pp. 357-389

Vinatea Recoba, Martina (2009) Epístola de Amarilis a Belardo. Madrid: Iberoamericana-Vervuert 